\title{
Dynamic Coding of Taste Stimuli in the Brainstem: Effects of Brief Pulses of Taste Stimuli on Subsequent Taste Responses
}

\author{
Patricia M. Di Lorenzo, Christian H. Lemon, and Christian G. Reich \\ State University of New York at Binghamton, Binghamton, New York 13902
}

Recent studies have suggested that the response profiles of taste-responsive cells in the brainstem may be modulated by inhibitory interactions, potentially originating from activity in peripheral taste nerves. This idea was explored by testing the hypothesis that brief $(100 \mathrm{msec})$ pulses of taste stimuli would alter the responses to subsequently presented tastants in the nucleus of the solitary tract (NTS) of urethane-anesthetized rats. Pulses of taste stimuli, called prepulses, were followed by a 3 sec presentation of the same or different taste stimulus. The prepulse-stimulus interval was either 1 or $5 \mathrm{sec}$, during which the tongue was rinsed with distilled water. Taste stimuli consisted of $0.1 \mathrm{M} \mathrm{NaCl}, 0.5 \mathrm{~m}$ sucrose, $0.01 \mathrm{~m}$ quinine $\mathrm{HCl}$, and $0.01 \mathrm{M} \mathrm{HCl}$. Taste prepulses suppressed (or enhanced) subsequent taste responses in 30 of $49(61 \%)$ units when the prepulse-stimulus interval was $1 \mathrm{sec}$ but were ineffective when this interval was 5 sec. Most commonly, $\mathrm{NaCl}$ or $\mathrm{HCl}$ prepulses attenuated the response to quinine. Control experiments showed that these effects were not attributable to adaptation, mixture effects, or response variability. In 19 (39\%) of the units tested, effects of prepulses were large enough to change the order of effectiveness of the taste stimuli. Taste responses in these cells were "dynamically tuned" in that the magnitude of response was a function of the taste stimulus that immediately preceded it. Dynamic tuning may be the result of inhibitory interactions within the NTS; cells that show dynamic tuning may have a unique function in taste coding.

Key words: taste; gustatory; neural coding; electrophysiology; nucleus of the solitary tract; inhibition

\section{Introduction}

At all levels of the nervous system, most taste-responsive cells are multisensitive across taste qualities (salty, sweet, bitter, and sour). At a fixed set of concentrations, the relative response magnitude of a given taste cell to exemplars of these qualities, defined as its response profile, is thought to be a reliable, defining characteristic. However, recent studies have suggested that response profiles in the brainstem may be altered by blocking inhibitory activity (Smith and Li, 1998). This suggests that the response profile of a taste cell may be a changeable characteristic that is modulated by inhibitory input.

Although the origin of activity that initiates and/or sustains inhibitory activity in the brainstem taste nuclei is not known, some studies have suggested that afferent activity from peripheral taste nerves may play a direct role. For example, Grabauskas and Bradley (1996) have reported that electrical stimulation of the solitary tract in vitro evokes IPSPs in cells in the rostral central subdivision of the nucleus of the solitary tract (NTS), the first synaptic relay in the gustatory system (Hamilton and Norgren, 1984). These authors suggested that such feedforward inhibition was most likely evoked through the activation of inhibitory inter-

Received March 13, 2003; revised July 29, 2003; accepted July 31, 2003.

This work was supported by National Science Foundation Grant IBN9630326 (P.M.D.).

Correspondence should be addressed to Patricia M. Di Lorenzo, Department of Psychology, Box 6000, State University of New York at Binghamton, Binghamton, NY 13902-6000. E-mail: diloren@binghamton.edu.

C. H. Lemon's present address: Department Anatomy and Neurobiology, University of Tennessee College of Medicine, 855 Monroe Avenue, Suite 515, Memphis, TN 38163. E-mail: clemon@utmem.edu.

C. G. Reich's present address: Department of Physiology, University of Maryland School of Medicine, 655 West Baltimore Street, Baltimore, MD 21201. E-mail: creich@som.umaryland.edu.

Copyright $\odot 2003$ Society for Neuroscience $\quad$ 0270-6474/03/238893-10\$15.00/0 neurons. In a subsequent report, Grabauskas and Bradley (1998) showed that tetanic pulse trains of electrical stimulation to the solitary tract could potentiate inhibitory potentials in the NTS. In the intact rat, Lemon and Di Lorenzo (2002) delivered tetanic trains of electrical pulses to the chorda tympani nerve (CT) (innervating taste buds on the rostral two-thirds of the tongue) and recorded the effects on response profiles in cells in the NTS. Results showed that taste responses could be altered by tetanic CT stimulation in a stimulus-selective manner. Furthermore, NTS field responses evoked by paired-pulse stimulation of the CT revealed evidence of an inhibitory influence that could be detected for $\sim 2 \mathrm{sec}$.

If one effect of afferent peripheral nerve activity is to invoke inhibitory potentials in NTS cells, then it is possible that some evidence of this influence would be detectable with natural taste stimulation. Furthermore, any effect of natural stimulation on subsequent taste responses might be expected to have a measurable time course similar to that of CT stimulation. To test this hypothesis, brief (100 msec) pulses of taste stimuli, called prepulses, were presented shortly before the same or a different taste stimulus in the present study. Results confirmed that taste response profiles in the NTS could be altered by the presentation of taste prepulses in ways that resembled the effects of tetanic CT stimulation on NTS taste responses. Importantly, in a subset of cells, responses to a given stimulus differed depending on the identity of the stimulus that immediately preceded it. These data suggest that the sensitivity of some taste cells in the NTS may be a dynamic characteristic of their response patterns. Furthermore, different roles for cells with and without dynamically tuned responses is suggested. 
Parts of this work have been published previously in abstract form (Di Lorenzo, 2000).

\section{Materials and Methods}

Subjects. Forty-two male rats (250-350 gm) of the Sprague Dawley strain were used in these experiments. All animals were housed individually in stainless steel cages and maintained at $22^{\circ} \mathrm{C}$ on a $12 \mathrm{hr}$ light/dark cycle with lights on at 7:00 A.M. Fresh rat chow and water were available ad libitum.

Surgery. Initially, rats were anesthetized with urethane (1.5 gm/kg, i.p., administered in two equal doses spaced $30 \mathrm{~min}$ apart) and prepared surgically for electrophysiological recording in the NTS. Animals were tracheotomized and mounted in a stereotaxic instrument so that the head was positioned with the tooth bar $5 \mathrm{~mm}$ below the interaural line. This position allowed access to the NTS without disruption of any sinuses or major blood vessels. The occipital bone was removed, and uvular and nodular portions of the cerebellum were aspirated gently to expose the dorsal surface of the caudal medulla. Core temperature was monitored with a rectal thermometer linked to a heating pad and maintained at $37^{\circ} \mathrm{C}$.

Recording. Single units in the NTS were located and recorded with tungsten microelectrodes $(18-20 \mathrm{M} \Omega$ at $1 \mathrm{kHz}$; Frederick Haer Company, Bowdoinham, ME). Signals from the electrodes were fed through an amplifier (P511; Astro-Med, West Warwick, RI) and recorded on a PCM recorder (Vetter Instruments, Rebersburg, PA) for later playback and analysis. Initially, the electrode was placed over the obex, a position that served as a point of reference. Previous work in our laboratory has shown that the taste-responsive portion of the NTS is located $\sim 2.7 \mathrm{~mm}$ rostral and $1.8 \mathrm{~mm}$ lateral to the obex and $0.8-1.8 \mathrm{~mm}$ below the dorsal surface of the medulla. As the electrode was advanced into the medulla, the presence of taste responses was tested by bathing the tongue with 0.1 $\mathrm{M} \mathrm{NaCl}(5 \mathrm{sec})$, followed by a rinse of distilled water $(20 \mathrm{sec})$. To prevent a sampling bias in the cells chosen for analysis, once the electrode detected a response to $\mathrm{NaCl}$ in the background, every isolated cell was tested with all four taste stimuli. Action potentials recorded from single units were identified based on waveform consistency, which was continuously monitored throughout each recording session. Offline analysis, described below, was used to verify the isolation of every unit throughout the entire experimental protocol.

Stimuli and stimulus delivery. Taste stimuli were chosen as prototypical representatives of the four "basic" taste qualities, i.e., salty, sweet, bitter, and sour. They consisted of $0.1 \mathrm{M} \mathrm{NaCl}, 0.5 \mathrm{~m}$ sucrose, $0.01 \mathrm{M}$ quinine $\mathrm{HCl}$, and $0.01 \mathrm{M} \mathrm{HCl}$. All stimuli were made with reagent grade chemicals, dissolved in distilled water, and presented at room temperature. The concentrations chosen for each stimulus evoked half-maximal responding from the rat CT nerve (Ganchrow and Erickson, 1970; Ogawa et al., 1974).

Taste stimuli were bathed over the tongue through a specially designed stimulus delivery system. A bundle of five stainless steel tubes drilled with tiny holes on top and bottom were positioned in the mouth so that the holes were facing the tongue surface and palate. These tubes were connected to reservoirs of tastants with polyethylene tubing (PE 140; Intramedic) through an array of solenoid valves. Each tube was associated with its own fluid reservoir containing a taste stimulus or distilled water. Compressed air introduced into each of the reservoirs kept the fluid pressurized. When a solenoid valve was operated, fluid bathed the entire mouth, including the nasoincisor ducts. Because of the position of the holes along the tubes and because the flow rate was so high $(300 \mathrm{ml} / \mathrm{min})$, the entire mouth was flooded almost immediately. When the solenoid closed, flow of the stimulus stopped without dripping because of the surface tension of the liquid in the tubes. It was possible to infuse stimulus pulses of as little as $30 \mathrm{msec}$ with this system. Stimulus delivery was controlled by a computer that operated the solenoid valves.

Testing. Initially, each of four taste stimuli ( $\mathrm{NaCl}$, sucrose, quinine, or $\mathrm{HCl}$ ) was presented in individual trials consisting of a $10 \mathrm{sec}$ baseline (spontaneous activity), a $10 \mathrm{sec}$ stimulus presentation, a $10 \mathrm{sec}$ wait, and a $20 \mathrm{sec}$ distilled water rinse. These parameters were the standards used in our laboratory in previous work (Di Lorenzo and Lemon, 2000; Lemon and Di Lorenzo, 2002). However, because the testing protocol in the present study was particularly long, we decided to shorten the stimulus presentation to $3 \mathrm{sec}$ for subsequent trials. Therefore, after the initial four stimulus presentations, each stimulus was presented as a $100 \mathrm{msec}$ prepulse, followed immediately by $1 \mathrm{sec}$ of water rinse and a $3 \mathrm{sec}$ presentation of another (test) stimulus. Each prepulse-test stimulus combination was presented until each stimulus had served as both prepulse and test stimulus. The following control conditions were also presented: water rinse for $1 \mathrm{sec}$, followed by a $3 \mathrm{sec}$ stimulus presentation (no taste prepulse); taste prepulse, $5 \mathrm{sec}$ water rinse, $3 \mathrm{sec}$ stimulus presentation; and water rinse for $5 \mathrm{sec}$, followed by a $3 \mathrm{sec}$ stimulus (no taste prepulse). A 20 sec distilled water rinse always followed the test stimulus after a $10 \mathrm{sec}$ wait. Additional trials sometimes presented both stimuli simultaneously as a control for mixture effects. There were also occasions in which the response to each stimulus of a pair were recorded after adaptation of the tongue to the other tastant of the pair. The adaptation procedure was identical to that described by Di Lorenzo and Lemon (2000). Finally, in some cases, the four taste stimuli were presented individually for a second time, as in the initial four trials, at the end of the protocol. Intertrial intervals were $2 \mathrm{~min}$.

Data analysis. Isolation of single units was accomplished using the Discovery data acquisition package from DataWave Technologies (Longmont, CO) as follows. An amplitude discriminator was used initially to select waveforms that exceeded the background activity level. Next, eight metrics (e.g., spike amplitude, spike width, and spike valley duration) were derived for each waveform, and the results were plotted in a metric versus metric manner. Waveforms showing uniform shape and amplitude produced points in these plots that were grouped close together; the area within each plot that contained a cluster of these points was considered to be indicative of the waveform from a single unit. Action potentials were stamped with the time of occurrence (resolution of $1 \mathrm{msec}$ ) relative to the beginning of each stimulus trial. Action potentials from single units were converted to time-stamped transistortransistor logic pulses (sampling rate of $32 \mathrm{kHz}$ ).

Peristimulus time histograms were constructed with a time bin of 100 msec. Response magnitude was measured as the rate of firing in spikes per second (sps) in the first $3 \mathrm{sec}$ of the response minus the firing rate in the baseline period (the $10 \mathrm{sec}$ preceding the stimulus). An increase in the average firing rate over the first $3 \mathrm{sec}$ of stimulus presentation that differed from the average baseline rate by at least 2.54 SDs was defined as a response. This response interval was chosen because it encompassed the entire interval when the stimulus was flowing over the tongue. Physiologically, this interval also contained both initial phasic and the later tonic components of the responses. Mean response rates are expressed as the mean \pm SEM.

A significant effect of a taste prepulse on the subsequently presented taste response was defined as a change of at least $50 \%$ from the response without a prepulse. For responses that were (arbitrarily) $<5 \mathrm{sps}$, a change of at least $100 \%$ was required. These conservative criteria were adopted to ensure that any effects that were detected were truly significant, given that it was not possible to replicate stimulus presentations in such a long stimulus presentation protocol.

To examine the breadth of tuning of taste-responsive NTS cells, an uncertainty measure (Smith and Travers, 1979) was calculated for each unit as follows:

$$
H=-K\left(\sum_{i=1}^{4} P_{i} \log P_{i}\right)
$$

where $P_{i}$ represents the response to each stimulus expressed as a proportion of the total response to $n$ stimuli, and $K$ is a scaling constant. For four stimuli, $K=1.661$, which results in $H$ ranging from a minimum of 0 (unit responds to only one stimulus) to a maximum of 1 (unit responds equally well to all stimuli). Mean uncertainty values are expressed as the mean \pm SEM.

Units were labeled initially according to the stimulus that evoked the greatest response magnitude, i.e., their "best" stimulus. Thereafter, units were grouped according to the results of hierarchical cluster analysis (HCA). In this procedure, units are joined into groups or "clusters" based on a measure of similarity of their response profiles, defined as the relative response rates across taste stimuli. Initially, the two most similar 
response profiles are joined into a cluster. Then, the next most similar response profiles and/or clusters of response profiles are joined. The analysis proceeds in a stepwise manner until all response profiles are joined into a single cluster containing all of the units. A plot of the progression of the analysis showing the clustering pattern and the degree of dissimilarity (plotted as distances) among clusters at various stages of the analysis is called a dendrogram. In the present study, the Pearson product-moment correlation was used as a measure of across-unit similarity; all responses, both without and after taste prepulses, were used. The SYSTAT program (Systat Software, Richmond, CA) on a Macintosh computer (Apple Computers, Cupertino, CA) was used to perform the HCA; the Ward minimum variance linkage algorithm was applied.

In addition to the analysis of the effects of taste prepulses on the response magnitude to various tastants, the incidence and function of dynamic tuning, defined as the susceptibility of a unit to the effects of taste prepulses, was also studied. To assess the effects of dynamic tuning on taste coding, units were divided into two groups based on the effectiveness of taste prepulses in altering their response profiles. According to the labeled line theory of taste coding, the best stimulus of a unit indicates the taste quality that a unit encodes (Scott and Giza, 1990; Giza and Scott, 1991). Therefore, a change in the best stimulus that occurred as a result of preceding tastants with prepulses was used as a criterion for classifying units as "dynamically tuned." Accordingly, units in which taste prepulses altered the magnitude of taste responses to such an extent that the best stimulus was changed were designated as "dynamically tuned units" (DTUs). Units in which taste prepulses did not affect the best stimulus were designated as "signal units," reflecting the stability of their role in the coding process (Di Lorenzo, 2000). Functional differences between these two groups of units were then examined.

To examine the organization of across-unit patterns of response evoked by each stimulus, multidimensional scaling (MDS) was used. This analysis places taste stimuli within a hypothetical "taste space" based on the degree of similarity (measured as the Pearson product-moment correlation) of their evoked response magnitudes across units. Stimuli that evoke a similar across-unit pattern of response are placed close to each other, and those with dissimilar across-unit patterns of response are placed relatively far apart. Separate MDS analyses were conducted for all units considered together, for signal units and for DTUs. The SYSTAT program on a Macintosh computer was used for this analysis.

\section{Results}

Electrophysiological responses to taste stimuli in the prepulse paradigm were recorded from 49 single units in the NTS. In five animals, two units were isolated from the same electrode, and in one animal it was possible to isolate three units from the same electrode. Average spontaneous firing rate was $1.7 \pm 0.3 \mathrm{sps}$. In general, NTS units were broadly responsive across the tastants tested: $\sim 90 \%$ of the sample responded to more than one of the tastants tested. The order of effectiveness, as measured by mean response rate across the sample, was $\mathrm{NaCl}>\mathrm{HCl}>$ quinine $>$ sucrose. Thirty units (61\%) showed at least one taste response that was significantly different when it was preceded by a prepulse of at least one taste stimulus. Nineteen units (39\%) showed attenuated responses after one or more taste prepulses, and 12 units (24\%) showed enhanced responses after one or more taste prepulses. One unit showed enhanced responses to $\mathrm{NaCl}$ after prepulses of sucrose, $\mathrm{HCl}$, or quinine (but not after an $\mathrm{NaCl}$ prepulse) and an attenuated response to quinine after an $\mathrm{NaCl}$ prepulse.

\section{Responses to prepulses}

Of the 784 trials in which a $100 \mathrm{msec}$ prepulse of a taste stimulus was presented before a $5 \mathrm{sec}$ taste stimulus, $523(67 \%)$ of these prepulse presentations produced a response in an NTS unit. The average length of the response to the prepulse was $480 \pm 10 \mathrm{msec}$. The average response rates associated with prepulses of each tastant were as follows: $\mathrm{NaCl}, 16.1 \pm 2.3 \mathrm{sps} ; \mathrm{HCl}, 12.7 \pm 2.5$ sps; quinine, $8.1 \pm 1.3 \mathrm{sps}$; and sucrose, $6.0 \pm 0.9 \mathrm{sps}$. These values were comparable with the average response rates produced by taste stimuli that were not preceded by a prepulse: $\mathrm{NaCl}, 14.6 \pm$ $2.1 \mathrm{sps} ; \mathrm{HCl}, 14.0 \pm 2.5 \mathrm{sps}$; quinine, $7.2 \pm 1.3 \mathrm{sps}$; and sucrose, $7.6 \pm 1.0$ sps.

The water rinse after the prepulse was effective in terminating the response. Overall, there was an average of $600 \pm 100 \mathrm{msec}$ after the prepulse in which there were no spikes at all between the prepulse and the response to the subsequent stimulus. There were only $15(3 \%)$ occasions in which spike activity produced by the prepulse did not return to zero in the interval between the prepulse and the test stimulus.

To address the issue of whether cross-adaptation might account for the effects of prepulses on responses to subsequently presented taste stimuli, trials in which the prepulse and the test stimulus were identical were examined. These prepulses were called autopulses. Of 112 trials in which the taste response was (arbitrarily) $>5 \mathrm{sps}$, an autopulse attenuated the subsequent response by $>50 \%$ on only 13 ( $12 \%)$ occasions. Overall, the average difference in response rate between the response to a taste stimulus without a prepulse and one that was preceded by a prepulse was as follows: $\mathrm{NaCl}, 0.9 \pm 0.9$ sps; $\mathrm{HCl}, 2.4 \pm 0.8$ sps; quinine, $0.01 \pm 0.7 \mathrm{sps}$; and sucrose, $0.04 \pm 0.7 \mathrm{sps}$. Because the evidence does not support the idea that autopulses produced adaptation, the effect of a prepulse of a given taste stimulus on the response to a different taste stimulus is unlikely to be the result of adaptation.

\section{Effects of prepulses on taste response magnitude}

Figure 1 illustrates the types of prepulse effects that were seen. Figure $1, A$ and $B$, shows an example of the effects of a $\mathrm{NaCl}$ prepulse on the subsequent response to quinine in one unit. In Figure $1 A$, top, a prepulse of quinine was followed by $1 \mathrm{sec}$ of water and a $3 \mathrm{sec}$ presentation of quinine. In Figure $1 A$, middle, an $\mathrm{NaCl}$ prepulse preceded a $1 \mathrm{sec}$ water rinse and a $3 \mathrm{sec}$ quinine response. It can be seen that the quinine response in this case was nearly absent. When the 3 sec quinine presentation was preceded only by $1 \mathrm{sec}$ water rinse (Fig. $1 \mathrm{~A}$, bottom), the quinine response was intact. When the interval between the prepulse was lengthened to $5 \mathrm{sec}($ Fig. $1 \mathrm{~B})$, there was no effect of a $\mathrm{NaCl}$ prepulse on the subsequent response to quinine.

Figure 2 shows the mean response rates for each stimulus presented without a prepulse and for each prepulse-stimulus combination. Responses to sucrose $\left(F_{(48,4)}=0.29 ; p>0.05\right)$ and $\mathrm{NaCl}\left(F_{(48,4)}=1.66 ; p>0.05\right)$ were, on average, not affected by prepulses of any stimulus; however, prepulses of $\mathrm{NaCl}$ and $\mathrm{HCl}$ were reliably associated with attenuated responses to $\mathrm{HCl}$ and quinine. For quinine responses, there was a main effect of prepulse $\left(F_{(48,4)}=10.29 ; p<0.01\right)$. Newman-Keuls pairwise comparisons showed that the response to quinine after an $\mathrm{NaCl}$ prepulse was significantly lower than the response to quinine presented alone $(p<0.01)$ or preceded by a prepulse of any other tastant ( $p$ values $<0.05$ ). In addition, responses to quinine preceded by an $\mathrm{HCl}$ prepulse were also significantly lower than responses to quinine presented alone or with a quinine prepulse ( $p$ values $<0.01)$. For $\mathrm{HCl}$ responses, there was also a main effect of prepulse $\left(F_{(48,4)}=6.51 ; p<0.01\right)$. Newman-Keuls pairwise comparisons showed that the response to $\mathrm{HCl}$ was significantly attenuated by either an $\mathrm{NaCl}$ prepulse $(p$ values $<0.01$ ) or by an $\mathrm{HCl}$ prepulse $(p$ values $<0.05$ ). In general, the average uncertainty measure did not change appreciably when taste stimuli were recorded after prepulses: average uncertainty when stimuli were presented without a prepulse was $H=0.78 \pm 0.02$; when 


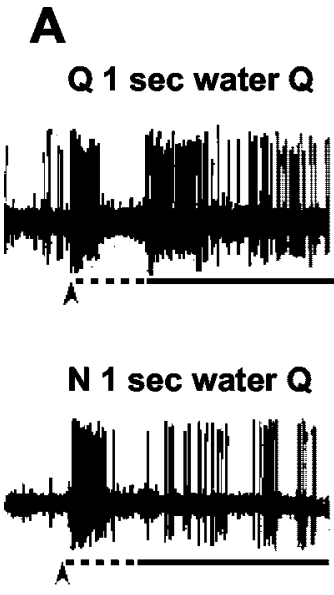

1 sec water $Q$

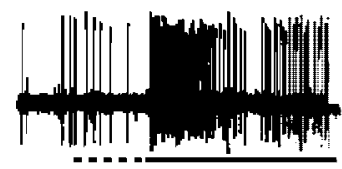

B

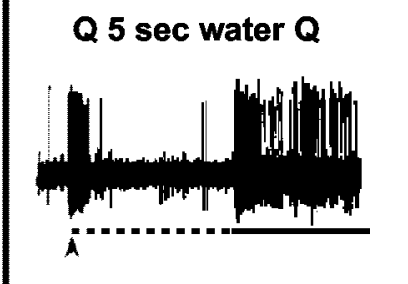

N 5 sec water $\mathbf{Q}$

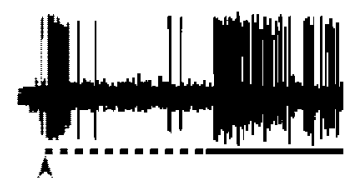

5 sec water $Q$

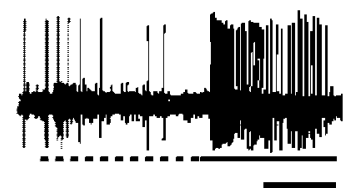

Figure 1. Oscilloscope tracings from one cell. Arrow under each trace indicates onset of taste prepulse; dotted line under each trace indicates presentation of water rinse; solid line under each trace indicates stimulus presentation. Calibration bar (bottom right): $A, 1 \mathrm{sec} ; B, 2 \mathrm{sec}$. $A$, Top, Response to a 100 msec quinine prepulse, followed by a $1 \mathrm{sec}$ water rinse and a $3 \mathrm{sec}$ quinine stimulus presentation. Middle, Response to a $100 \mathrm{msec} \mathrm{NaCl}$ prepulse, followed by a 1 sec water rinse and a $3 \mathrm{sec}$ quinine stimulus presentation. Bottom, Response to a $1 \mathrm{sec}$ water rinse, followed by a 3 sec quinine stimulus. $B$, Top, Response to a 100 msec quinine prepulse, followed by a $5 \mathrm{sec}$ water rinse and a $3 \mathrm{sec}$ quinine stimulus. Middle, Response to a $100 \mathrm{msec}$ $\mathrm{NaCl}$ prepulse, followed by a $5 \mathrm{sec}$ water rinse and $3 \mathrm{sec}$ quinine stimulus. Bottom, Response to a 5 sec water rinse, followed by a 3 sec quinine stimulus.

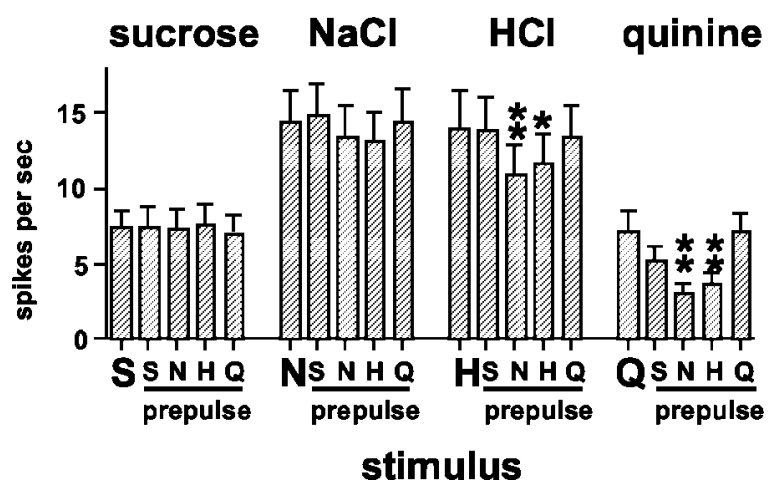

Figure 2. Mean \pm SEM response rates (in spikes per second) to taste stimuli presented alone or when a taste prepulse preceded the stimulus by $1 \mathrm{sec}$. Large letters along abscissa indicate stimulus presentation without a prepulse. Smaller letters along abscissa indicate the stimulus used as a prepulse. S, Sucrose; $\mathrm{N}, \mathrm{NaCl} ; \mathrm{H}, \mathrm{HCl} ; \mathrm{Q}$, quinine. ${ }^{*} p<0.05$; ${ }^{* *} p<0.01$. For details of statistical analyses, see Results.

stimuli were preceded by an $\mathrm{NaCl}$ prepulse, $H=0.75 \pm 0.02$; when stimuli were preceded by an $\mathrm{HCl}$ prepulse, $H=0.76 \pm$ 0.02 ; when stimuli were preceded by a quinine prepulse, $H=$ $0.77 \pm 0.02$; and when stimuli were preceded by a sucrose prepulse, $H=0.77 \pm 0.02$.

In 25 NTS units, control trials were completed in which the prepulse-stimulus interval was $5 \mathrm{sec}$ and in which water was presented for 1 or $5 \mathrm{sec}$ without a taste prepulse. The mean response rates for all of these trials are presented in Figure 3. Prepulses of either $\mathrm{NaCl}$ or $\mathrm{HCl}$ significantly attenuated the sub-
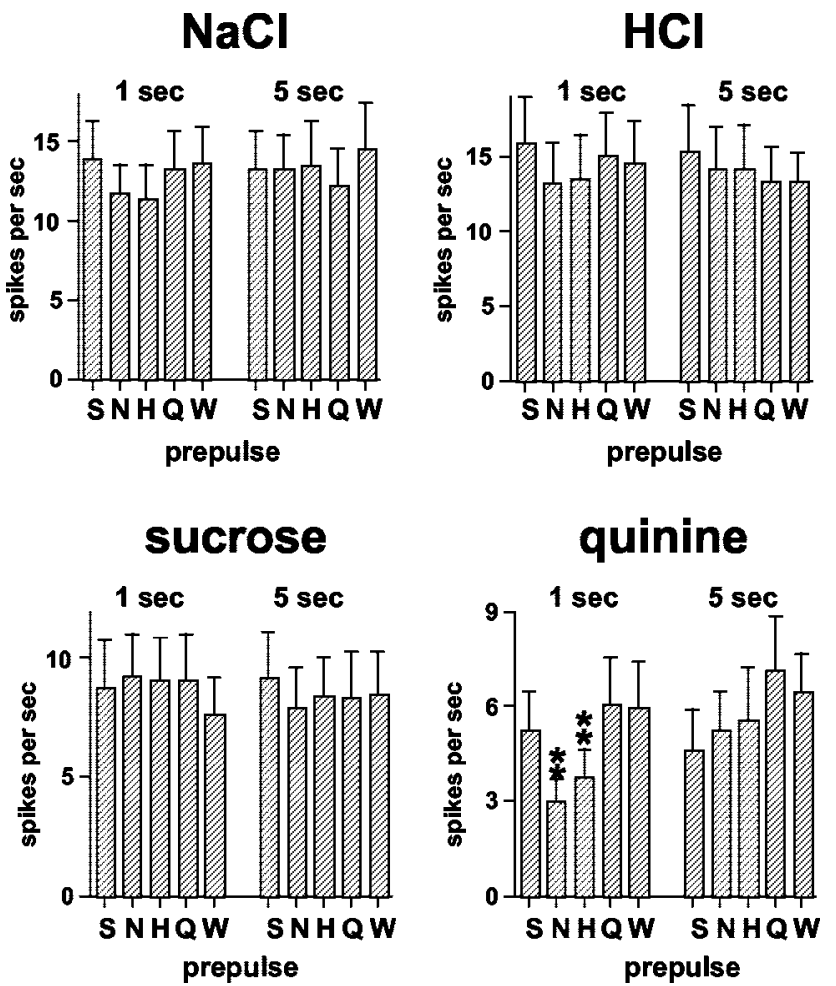

Figure 3. Mean \pm SEM response rates (in spikes per second) to taste stimuli presented alone or preceded by taste prepulses. $1 \mathrm{sec}$, Prepulse-stimulus interval was $1 \mathrm{sec}$, during which a water rinse was presented. $5 \mathrm{sec}$, Prepulse-stimulus interval was $5 \mathrm{sec}$, during which a water rinse was presented. Letters along abscissa indicate the stimulus that was used as a prepulse. $S$, Sucrose; $\mathrm{N}, \mathrm{NaCl} ; \mathrm{H}, \mathrm{HCl} ; \mathrm{Q}$, quinine; $\mathrm{W}$, the response when the stimulus was preceded by a water rinse with no taste stimulus prepulse. ${ }^{*} p<0.05 ;{ }^{* *} p<0.01$. For details of statistical analyses, see Results.

sequent response to quinine at the 1 sec prepulse-stimulus interval but not the $5 \mathrm{sec}$ prepulse-stimulus interval. Statistical analyses of quinine responses showed a significant main effect of prepulse $\left(F_{(24,8)}=3.66 ; p<0.01\right)$. Pairwise comparisons of quinine responses showed that the response to quinine preceded by $1 \mathrm{sec}$, but not $5 \mathrm{sec}$, by an $\mathrm{NaCl}$ prepulse was significantly attenuated compared with the response when quinine was presented alone or when preceded by an autopulse at either the 1 or $5 \mathrm{sec}$ prepulse-stimulus interval ( $p$ values $<0.05$ ). Additionally, the response to quinine preceded by an $\mathrm{HCl}$ prepulse was significantly attenuated compared with the response to quinine preceded by 5 sec by an autopulse $(p<0.01)$. In trials in which water preceded the stimulus presentation without any taste prepulse, there was no effect on the subsequent response to the tastant ( $p$ values $>00.05)$.

Every taste stimulus used as a prepulse was associated with either or both enhanced and/or attenuated responses to other tastants. Figure 4 illustrates this point. In this figure, the response magnitude without a taste prepulse is plotted against the response magnitude after taste prepulses for each tastant. The dotted line in each graph represents the condition in which taste prepulses had no effect on the subsequent response. It can be seen that, in general, responses to sucrose and quinine were most often affected by taste prepulses, whereas relatively few responses to $\mathrm{NaCl}$ or $\mathrm{HCl}$ were affected (Fig. $4 A$ ). In Figure $4 B$, left, it can be seen that taste responses were not affected by water prepulses of either 1 or $5 \mathrm{sec}$. Figure $4 B$, right, shows that responses to taste stimuli were similar when presented initially or at the end of the experimental protocol. 
A
$\mathrm{NaCl}$
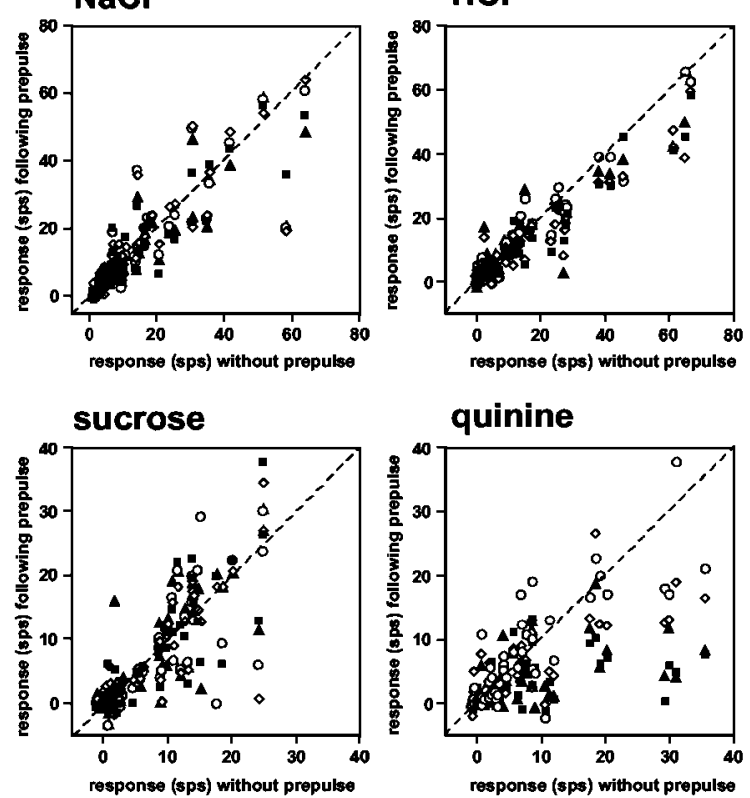

quinine

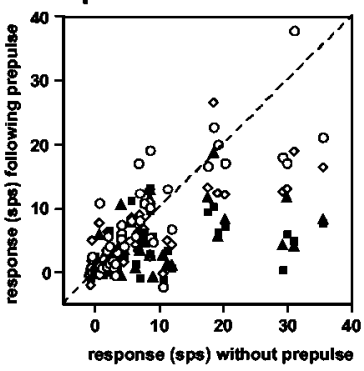

sucrose
B

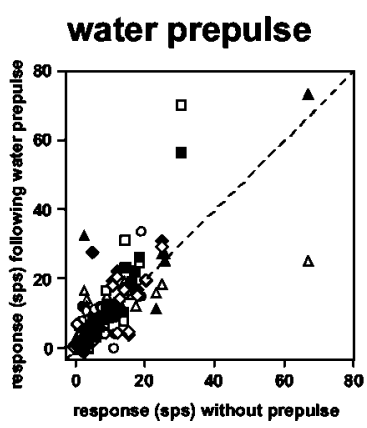

replications

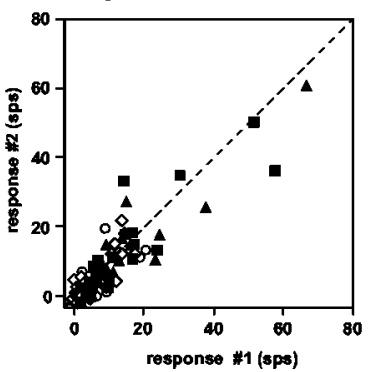

Figure 4. A, Response magnitude (in spikes per second) to taste stimuli for all units without (abscissa) and after (ordinate) taste prepulses. In each plot, the dotted line indicates the condition in which the response to the stimulus without a prepulse was equal to the response after a taste prepulse. Filled squares, Response without a prepulse versus after an $\mathrm{NaCl}$ prepulse; filled triangles, response without a prepulse versus after an $\mathrm{HCl}$ prepulse; open diamonds, response without a prepulse versus after a sucrose prepulse; open circles, response without a prepulse versus after a quinine prepulse. $B$, Left, Response magnitude (in spikes per second) to taste stimuli without taste prepulses (abscissa) versus after a 1 or $5 \mathrm{sec}$ water prepulse. Dotted line indicates the condition in which the response to the stimulus without a prepulse was equal to the response after a water prepulse. Squares, Response to $\mathrm{NaCl}$ after a $1 \mathrm{sec}$ (filled) or $5 \mathrm{sec}$ (open) water prepulse; triangles, response to $\mathrm{HCl}$ after a $1 \mathrm{sec}$ (filled) or $5 \mathrm{sec}$ (open) water prepulse; diamonds, response to sucrose after a $1 \mathrm{sec}$ (open) or $5 \mathrm{sec}$ (filled) water prepulse; circles, response to quinine after a $1 \mathrm{sec}$ (open) or $5 \mathrm{sec}$ (filled) water prepulse. B, Right, Response magnitude to taste stimuli (without taste prepulses) presented initially (abscissa) and at the end of the experimental protocol (ordinate). Dotted line indicates the condition in which the response to the stimulus initially was equal to the response after the experimental protocol. Filled squares, Response to $\mathrm{NaCl}$; filled triangles, response to $\mathrm{HCl}$; open diamonds, response to sucrose; open circles, response to quinine.

The degree of attenuation of taste responses to some tastants after a taste prepulse could be predicted by the magnitude of the response to the prepulse: the more spikes generated by a prepulse, the greater the attenuation of the subsequent taste response. The correlation between the response magnitude evoked by the prepulse and the magnitude of the attenuation of that prepulse on subsequent taste responses (as measured by the difference between the response magnitude without a prepulse minus the response magnitude after a prepulse) was $0.50(\mathrm{df}=308 ; p<$

\section{Attenuation following a taste prepluse}

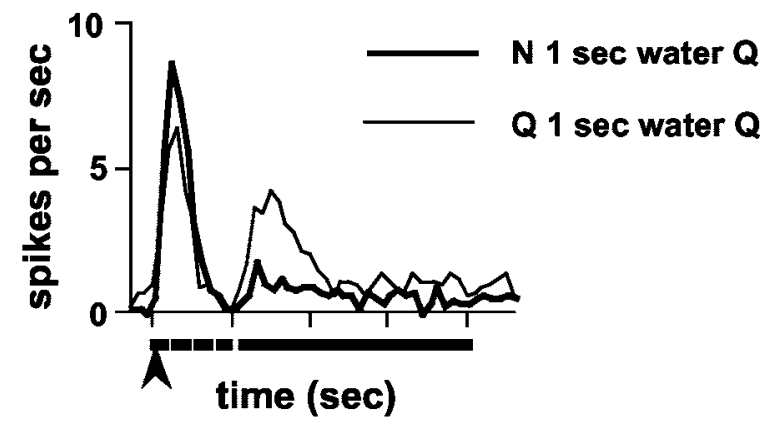

\section{Enhancement following a taste prepulse}

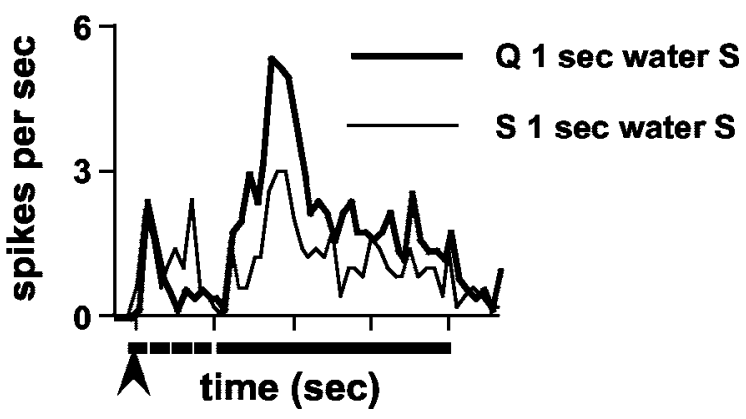

Figure 5. Examples of the time course of the effects of taste prepulses on subsequent taste responses. Top, Attenuation of quinine responses after an $\mathrm{NaCl}$ prepulse; mean response to quinine after an $\mathrm{NaCl}$ prepulse (thick line) or after a quinine prepulse (thin line); $n=13$. A water rinse was presented during the $1 \mathrm{sec}$ prepulse-stimulus interval. Bottom, Enhancement of sucrose response after a quinine prepulse; mean response to sucrose after a quinine prepulse (thick line) or after a sucrose prepulse (thin line); $n=5$. A water rinse was presented during the 1 sec prepulse-stimulus interval. Arrow under each graph indicates the presentation of the 100 msec prepulse; dotted line under each graph indicates the presentation of the $1 \mathrm{sec}$ water rinse; solid line under each graph indicates the presentation of the 3 sec stimulus.

0.001). The strongest association, i.e., highest positive correlation, was between the magnitude of the prepulse response to $\mathrm{NaCl}$ and the attenuation of subsequent quinine responses $(r=$ $0.81 ; \mathrm{df}=35 ; p<0.001)$.

When taste prepulses affected the responses to subsequently presented taste stimuli, the effects were not restricted to any specific portion of the time course of the response. Figure 5 illustrates the effect of taste prepulses on the time course of response. The average response to quinine preceded by an $\mathrm{NaCl}$ prepulse is superimposed on the average response to quinine after an autopulse ( $n=13$ units) in Figure 5, top. It is apparent that the attenuation of the quinine response after an $\mathrm{NaCl}$ prepulse could be seen throughout the entire time course of the response. Likewise, the average response to sucrose after a quinine prepulse is enhanced throughout its entire time course compared with the average sucrose response after an autopulse ( $n=5$ units) (Fig. 5, bottom).

Figure 6 shows an example of the appearance of a response to quinine after a prepulse of either $\mathrm{NaCl}$ or quinine itself in one NTS unit. Figure $6 A$ shows the responses to the four taste stimuli without any prepulses and the responses after autopulses. It can be seen that this cell responds well to $\mathrm{NaCl}$, moderately well to $\mathrm{HCl}$, and only weakly to sucrose and quinine. The response to quinine without any prepulse is only a very brief burst of a few 

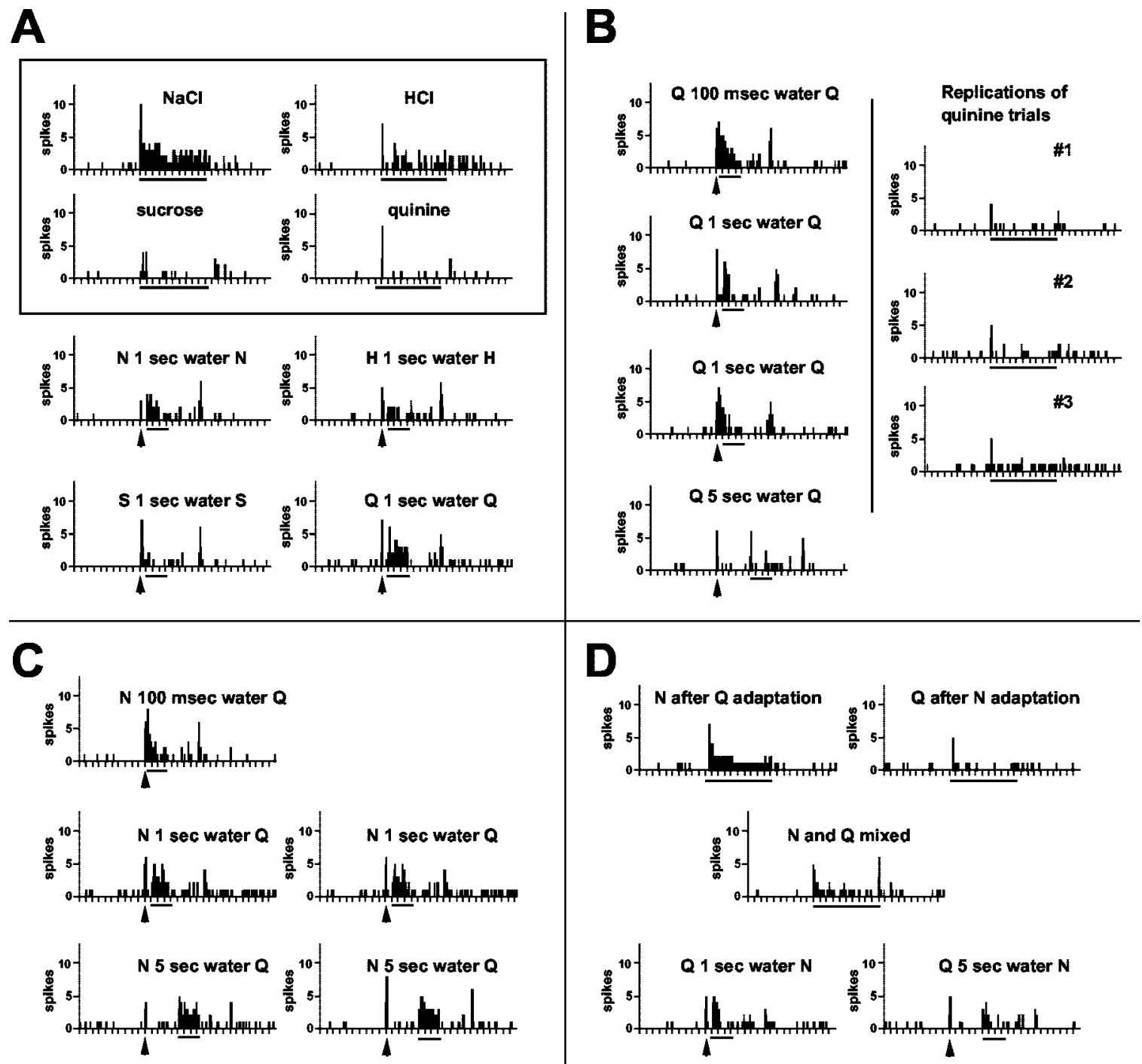

D
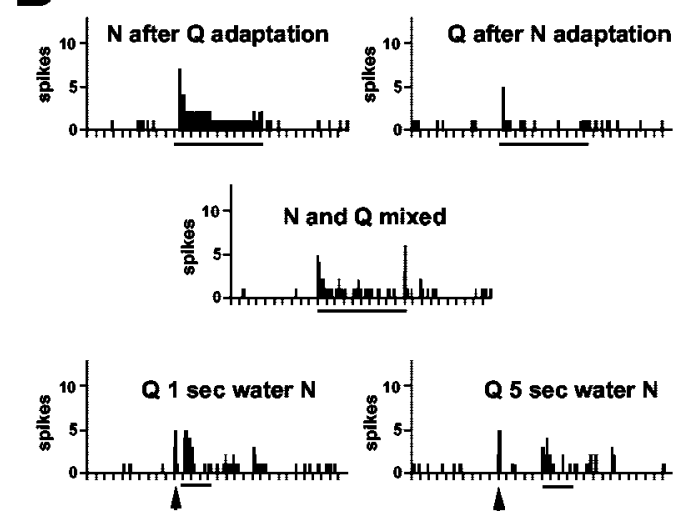

Figure 6. Peristimulus time histograms of responses to taste stimuli in one unit showing the appearance of a response to quinine after prepulses of NaCl or quinine. Arrow under histogram indicates presentation of a $100 \mathrm{msec}$ prepulse; line under each histogram indicates presentation of taste stimulus. A water rinse was always presented during the interval between the prepulse and the stimulus. Tick marks along the abscissa are time in seconds. S, Sucrose; $\mathrm{N}, \mathrm{NaCl} ; \mathrm{H}, \mathrm{HCl} ; \mathrm{Q}$, quinine. $A$, Top, Enclosed in a box, Responses to all four taste stimuli presented initially for 10 sec without taste prepulses; bottom, responses to taste stimuli presented for 3 sec preceded by an autopulse. B, Left, Responses to quinine presented for 3 sec preceded at various intervals (as indicated) by an autopulse. Right, Responses to replications of quinine presentations for $10 \mathrm{sec}$ without prepulses. These trials were interspersed at various points during the testing protocol. $C$, Responses to quinine preceded at various intervals (as indicated) by an $\mathrm{NaCl}$ prepulse. D, Top, Left, Response to a $10 \mathrm{sec} \mathrm{NaCl} \mathrm{presentation} \mathrm{after} \mathrm{adaptation} \mathrm{of} \mathrm{the} \mathrm{tongue} \mathrm{to} \mathrm{quinine.} \mathrm{Top,} \mathrm{Right,} \mathrm{Response} \mathrm{to} \mathrm{a} 10$ sec quinine presentation after adaptation of the tongue to $\mathrm{NaCl}$. Middle, Response to a mixture of $\mathrm{NaCl}$ and quinine presented for 10 sec. Bottom, Responses to a 3 sec $\mathrm{NaCl}$ presentation preceded by 1 sec (left) or $5 \mathrm{sec}$ (right) by a prepulse of quinine.

spikes. However, after an autopulse, a vigorous response to quinine is apparent. In Figure $6 B$, left, the interval between the quinine prepulse and the quinine stimulus was varied. The most vigorous response to quinine can be seen when the prepulsestimulus interval was reduced to $100 \mathrm{msec}$; the response was absent when the prepulse-stimulus interval was lengthened to $5 \mathrm{sec}$. Figure $6 B$, right, shows the lack of response to quinine presented without a prepulse in three trials that were presented intermittently throughout the session. In Figure $6 C$, it can be seen that prepulses of $\mathrm{NaCl}$ also enhanced the response to quinine at both short and long prepulse-stimulus intervals. In Figure $6 D$, it can be seen that the effects of $\mathrm{NaCl}$ prepulses are not the results of adaptation or mixture effects. In addition, it is evident that quinine prepulses do not have an enhancing effect on $\mathrm{NaCl}$ responses.

The possibility that the effects of taste prepulses on subse- quently presented taste stimuli were the result of simple variability with replication was examined in units in which prepulsestimulus trials were repeated. There were 28 units that were held long enough to present each of the four taste stimuli without prepulses for a second time (Fig. $4 B$ ). When only significant responses were considered (i.e., nonresponses were excluded from the analysis), responses to all tastants presented at the beginning of the experimental protocol were not significantly different than those presented at the end of the experimental protocol (Student's $t$ tests; $p$ values $>0.05$ ). The average percentage change from the initial to the second presentation was as follows: $\mathrm{NaCl}, 4 \pm 10 \%$; $\mathrm{HCl}, 6 \pm 9 \%$; quinine, $21 \pm 17 \%$; and sucrose, $14 \pm 12 \%$; positive value indicates attenuation. When taste stimuli were preceded by prepulses, the average difference between the response without a prepulse and the response after a prepulse was generally small (for $\mathrm{NaCl}$, between $-14 \pm 7 \%$ for sucrose 
Table 1. Pearson product-moment correlations of across-unit patterns of response

\begin{tabular}{llll}
\hline & $\mathrm{NaCl}$ & $\mathrm{HCl}$ & Quinine \\
\hline $\mathrm{HCl}$ & 0.67 & & \\
Quinine & 0.51 & 0.80 & \\
Sucrose & 0.15 & 0.20 & 0.08 \\
& $\mathrm{NaCl}$ & $\mathrm{HCl}$ & Quinine \\
$\mathrm{HCl}$ & 0.61 & & \\
Quinine & 0.35 & 0.62 & -0.10 \\
Sucrose & -0.04 & 0.07 &
\end{tabular}

Top, Correlations of across-unit patterns when tastants were presented without taste prepulses. Bottom, Correlations of across-unit patterns when tastants were preceded by taste prepulses. For example, the correlation between $\mathrm{NaCl}$ responses and $\mathrm{HCl}$ responses indicates the correlation between $\mathrm{NaCl}$ responses when preceded by an $\mathrm{HC}$ prepulse and $\mathrm{HCl}$ responses when preceded by an $\mathrm{NaCl}$ prepulse.

prepulse- $\mathrm{NaCl}$ response and $3 \pm 6 \%$ for $\mathrm{HCl}$ prepulse- $\mathrm{NaCl}$ response; for $\mathrm{HCl}$, between $-1 \pm 7 \%$ for quinine prepulse- $\mathrm{HCl}$ response to $23 \pm 5 \%$ for $\mathrm{NaCl}$ prepulse- $\mathrm{HCl}$ response; and for sucrose, between $1 \pm 8 \%$ for sucrose prepulse-sucrose response to $4 \pm 9 \%$ for quinine prepulse-sucrose response). For quinine responses, $\mathrm{NaCl}$ and $\mathrm{HCl}$ prepulses produced large changes in response magnitude on average $(50 \pm 12 \%$ for $\mathrm{NaCl}$ prepulsequinine response and $45 \pm 10 \%$ for $\mathrm{HCl}$ prepulses-quinine response) compared with those produced by an autopulse $(-7 \pm$ $13 \%)$ or a sucrose prepulse-quinine response $(24 \pm 10 \%)$.

\section{Effects of prepulses on NTS taste responses across units}

To determine the effects of taste prepulses on the across-unit patterns of responses, Pearson product-moment correlations were calculated for each pairwise comparison of taste stimuli. These are presented in Table 1, top and bottom. In Table 1, top, correlations of responses evoked by taste stimuli that were presented without prepulses are shown. In general, the smallest correlations were between sucrose and all other tastants; the largest correlation was between $\mathrm{HCl}$ and quinine. In Table 1, bottom, correlations of responses evoked by taste stimuli after prepulses are shown. For example, for the correlation between sucrose and $\mathrm{NaCl}$, responses to sucrose after a $\mathrm{NaCl}$ prepulse were compared with responses to $\mathrm{NaCl}$ after a sucrose prepulse. It can be seen that the effect of taste prepulses was to lower the interstimulus correlation for all pairwise comparisons, implying that the discrimination between tastants was improved. This effect was statistically significant only for the comparison of $\mathrm{HCl}$ with quinine responses (Fisher's $z$ transform, $z=1.79$; $p<0.05$ )

To explore the organization of response profiles before and after taste prepulses, an HCA was conducted, as described in Materials and Methods. The results are presented in Figure 7. Units are labeled according to their best stimulus and according to the magnitude of response to the best stimulus within their best stimulus category. Three groups of response profiles were suggested by this analysis: one group that was relatively narrowly tuned to sucrose $(S)$, another that was relatively narrowly tuned to $\mathrm{NaCl}(\mathrm{N})$, and a third that was relatively broadly tuned but which generally responded best to $\mathrm{HCl}(\mathrm{H})$. Importantly, statistical analyses of responses in individual clusters showed that the effects of prepulses of $\mathrm{NaCl}(p<0.01)$ and $\mathrm{HCl}(p<0.05)$ on responses to quinine were restricted to cells in the $\mathrm{H}$ cluster.

In addition to the susceptibility of the responses of units in the $\mathrm{H}$ cluster to the effects of taste prepulses, there were other functional characteristics that distinguished these units from others in the sample. For example, units in the H cluster were more broadly tuned than units in the $\mathrm{N}$ and $\mathrm{S}$ clusters: uncertainty for H cluster $=0.85 \pm 0.02$; uncertainty for $\mathrm{N}$ cluster $=0.67 \pm 0.04$; and

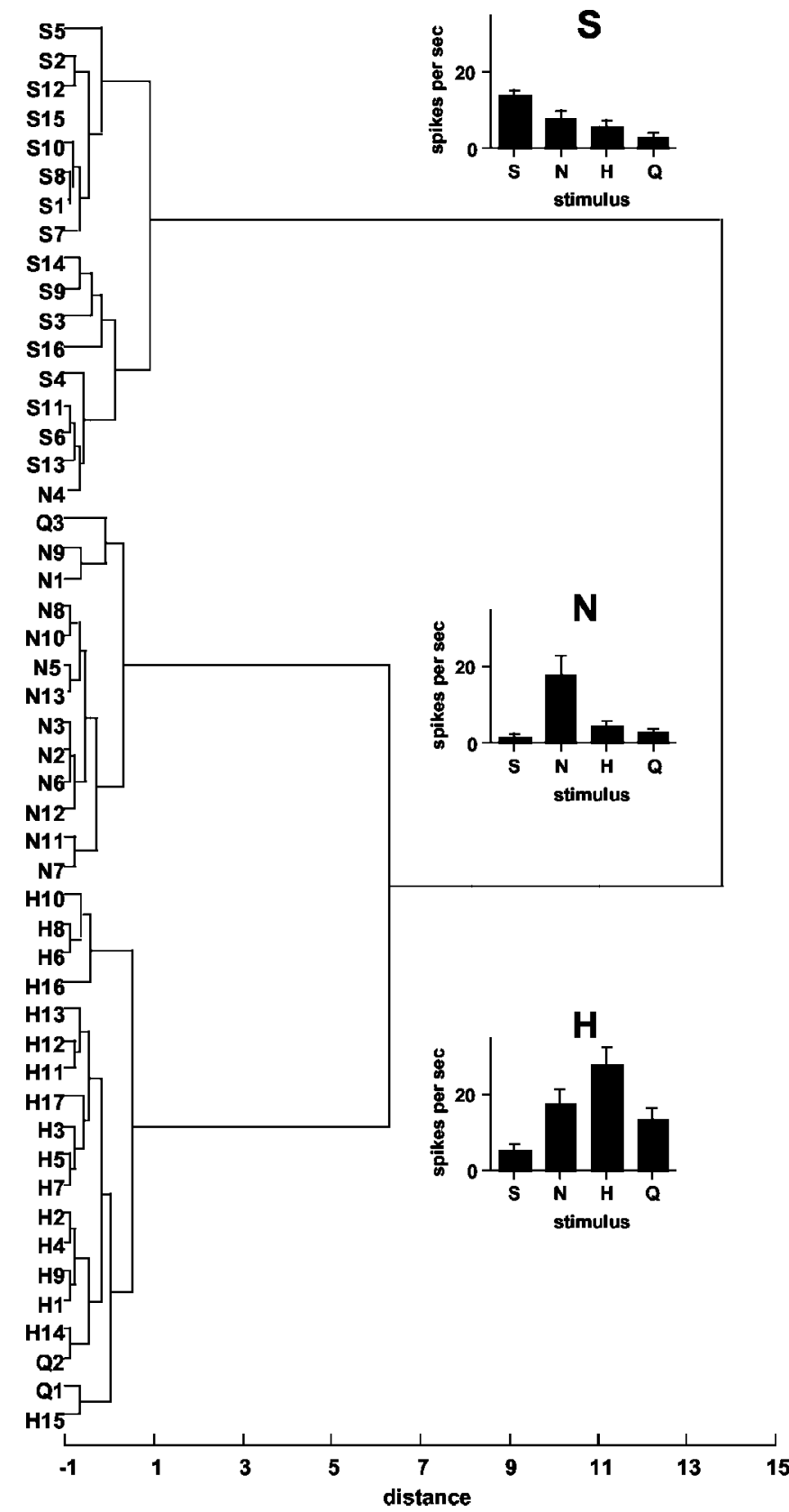

Figure 7. Dendrogram showing results of HCA. Units are labeled according to their best stimulus and their relative response magnitude to that stimulus within the best stimulus category. For example, $\mathrm{N} 3$ is an $\mathrm{NaCl}$ best unit with the third highest response to $\mathrm{NaCl}$ among the $\mathrm{NaCl}$ best units. Distance scale indicates relative dissimilarity of response profiles. Graphs show mean response rates (in spikes per second) for units in each of three clusters. Responses to taste stimuli presented without taste prepulses are shown. S, Sucrose; $\mathrm{N}, \mathrm{NaCl} ; \mathrm{H}, \mathrm{HCl} ; \mathrm{Q}$, quinine.

uncertainty for $\mathrm{S}$ cluster $=0.78 \pm 0.04$. In addition, among units in the $\mathrm{H}$ cluster, there was a statistically significant positive correlation $(r=0.38$; $\mathrm{df}=128 ; p<0.001)$ between the magnitude of the response to the prepulse and the magnitude of the attenuation of the prepulse (as measured by the difference between the response magnitude without a prepulse minus the response magnitude after a prepulse; only attenuated responses included). This relationship was particularly strong after a prepulse of $\mathrm{NaCl}$ in this cluster of units $(r=0.54 ; \mathrm{df}=39 ; p<0.001)$. Examination of the prepulse response magnitude associated with each tastant in each cluster (Fig. 8) showed that prepulses evoked by $\mathrm{NaCl}$ were 


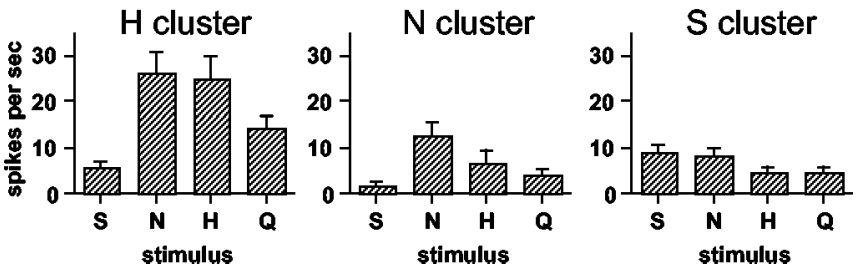

Figure 8. Mean $\pm \mathrm{SEM}$ firing rate (in spikes per second) in response to taste prepulses in units grouped by cluster. S, Sucrose; $\mathrm{N}, \mathrm{NaCl} ; \mathrm{H}, \mathrm{HCl} ; \mathrm{Q}$, quinine.

over twice as effective in units in the $\mathrm{H}$ cluster units as they were in units in the $\mathrm{N}$ and $\mathrm{S}$ clusters, although the response to $\mathrm{NaCl}$ in the $\mathrm{H}$ and $\mathrm{N}$ clusters were similar on average (Fig. 7). The magnitude of responses to prepulses of $\mathrm{HCl}$ and quinine was also quite large compared with that in the $\mathrm{N}$ and $\mathrm{S}$ clusters.

\section{Dynamic tuning and its effect on taste coding in the NTS}

To examine the role of dynamic tuning of response profiles, units were divided into those that were most affected by taste prepulses, called DTUs, and those that were relatively unaffected by taste prepulses. The best stimulus was altered when tastants were presented after prepulses in 19 (39\%) units; these units were therefore designated as DTUs. Those units whose best stimulus was unchanged by any prepulse condition $(n=30 ; 61 \%)$ were designated signal units, reflecting the constancy of their sensitivity pattern across tastants (Di Lorenzo, 2000). Figure 9 shows examples of the response profiles of three signal units (left) and three DTUs (right). It can be seen that taste responses in the signal units were relatively unaffected by taste prepulses, whereas taste responses in the DTUs were altered after prepulses to the extent that their best stimulus changed. Table 2 details the effects of prepulses on the distribution of units in the various best stimulus categories. Most notably, prepulses of $\mathrm{NaCl}$ and sucrose appeared to increase the proportion of $\mathrm{NaCl}$ best units. Among those units that changed their best stimulus, three were $\mathrm{NaCl}$ best, seven were $\mathrm{HCl}$ best, three were quinine best, and six were sucrose best. In relation to the results of the HCA, almost one-half of the DTUs (7 of $19 ; 47 \%)$ were members of the H cluster, whereas three $(16 \%)$ were members of the $\mathrm{N}$ cluster and seven (37\%) were members of the $\mathrm{S}$ cluster. Units that changed their best stimulus after prepulses, i.e., DTUs, were significantly more broadly tuned than those that did not change their best stimulus, i.e., signal units (mean uncertainty of those that changed best stimulus category, $0.84 \pm 0.02$; mean uncertainty of those that did not change their best stimulus category, $0.74 \pm 0.03$; Student's $t$ test; $p=0.012$ ).

To explore the organization of across unit patterns before and after taste prepulses, an MDS analysis was performed, as described in Materials and Methods. Figure 10, left, shows the results of this analysis applied to the present data. In this figure, all responses, i.e., those without and after taste prepulses, to sucrose and $\mathrm{NaCl}$ were grouped close to each other and relatively far away from responses to other tastants. Responses to $\mathrm{HCl}$ and quinine were placed relatively close to each other. However, the responses to quinine after prepulses of $\mathrm{NaCl}$ or $\mathrm{HCl}$ were placed far away from other responses to quinine; this may have been a reflection of the low response magnitude to quinine under these conditions.

MDS analyses were also used to explore whether signal units and DTUs served different functions in the coding process. The results are shown in Figure 10, middle and right. In the MDS associated with signal units (Fig. 10, middle), responses to sucrose and $\mathrm{NaCl}$ were grouped close together and relatively far from those to quinine and $\mathrm{HCl}$. In contrast, responses to quinine and $\mathrm{HCl}$ were relatively close to each other, with those evoked by quinine after prepulses of either $\mathrm{NaCl}$ or $\mathrm{HCl}$ separated from the rest. These results were quite similar to those when all units were included, except that the responses to quinine and $\mathrm{HCl}$ were more tightly associated in the analysis of signal units. In contrast, in the analysis associated with DTUs (Fig. 10, right), sucrose and quinine responses were grouped tightly and relatively far from those to $\mathrm{NaCl}$ and $\mathrm{HCl}$, which were placed close together. $\mathrm{Al}$ though the responses to quinine after prepulses of $\mathrm{NaCl}$ or $\mathrm{HCl}$ were somewhat segregated from the quinine "group," they were nevertheless placed closer to quinine than to responses associated with any other stimulus. Stress values for the three dimensional solutions for the MDS analyses were comparable: for all units, 0.03928; for signal units, 0.03847; and for DTUs, 0.04000 .

The MDS solutions associated with all units, signal units, and DTUs were compared by examining the correlation of the coefficients associated with each taste stimulus in each solution (Hair et al., 1998). The correlation of the coordinates of the MDS solution for all units compared with those for only signal units $(0.80)$ was significantly higher than the correlation of the MDS coordinates for all units compared with those for only DTUs (0.56; Fisher's $z=2.43 ; p<0.01)$ and the correlation of MDS coordinates for signal units compared with those for DTUs (0.55; Fisher's $z=2.49 ; p<0.01)$. This indicates that the MDS solution for all units and that for signal units were more similar to each other than either of them was to the MDS solution for DTUs.

\section{Discussion}

Taste responses from 49 single units in the NTS of anesthetized rats were recorded when taste stimuli were presented alone or after brief $(100 \mathrm{msec})$ pulses of the same or a different taste stimulus. In general, responses to tastants after prepulses of different taste stimuli were either attenuated or enhanced significantly in $30(61 \%)$ of the units tested. Although responses to all stimuli were affected by taste prepulses in some units, on average, the most common effect of taste prepulses was an attenuation of responses to quinine by $\mathrm{NaCl}$ and $\mathrm{HCl}$ prepulses. These latter effects were especially pronounced in $\mathrm{HCl}$ best units.

In 19 of $49(39 \%)$ units, taste prepulses were effective in changing the response magnitude to such a great extent that their best stimulus was changed. These units, representing a subset of each best stimulus category, responded to each stimulus differently depending on which stimulus just preceded it. Because of this characteristic, these units were called DTUs. DTUs were more broadly tuned than those cells whose responses were unaffected by taste prepulses. This latter group of units were called signal units. Although such a dichotomy may seem arbitrary, recent anatomical evidence suggests that narrowly and broadly tuned units in the NTS may be distinguished morphologically as well as functionally. That is, Renehan et al. (1996) found that narrowly tuned taste-responsive cells in the rat NTS had more dendritic branches and more spines than more broadly tuned cells regardless of their best stimulus. These narrowly and broadly tuned cells may correspond to the signal and DTUs, respectively, identified in the present study.

\section{Origin of the effects of prepulses on NTS taste responses}

There are several potential explanations for the effects of prepulses on taste responses in NTS units. For example, it is possible that the prepulses, although brief, were producing adaptation. However, the observation that neither autopulses nor water alone suppressed the taste responses on average is evidence against this idea. In those cases in which autopulses did produce attenuation 

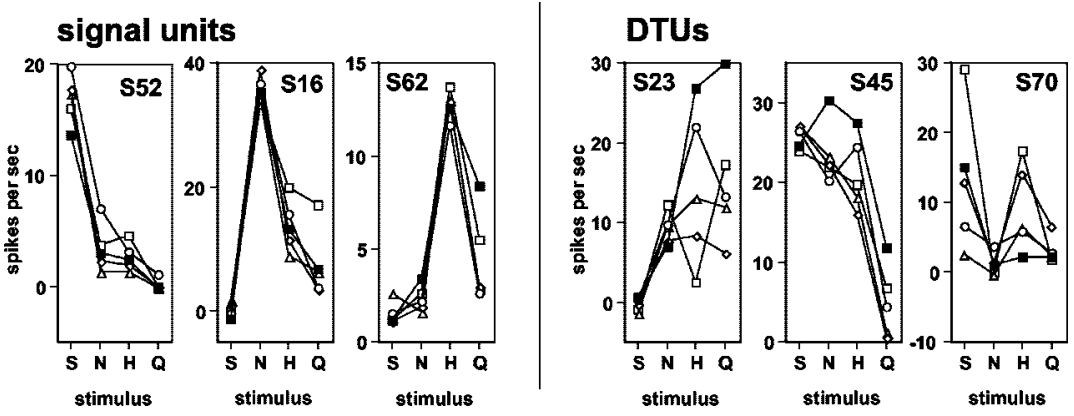

Figure 9. Response profiles of three signal units (left) and three DTUs (right) when taste stimuli were presented without and after taste prepulses. Label at top of each graph indicates the identity of the unit. S, Sucrose; $\mathrm{N}, \mathrm{NaCl} ; \mathrm{H}, \mathrm{HCl} ; \mathrm{Q}$, quinine. Filled squares, Responses when stimuli were presented without a prepulse; open circles, responses when stimuli were presented with a sucrose prepulse; open diamonds, responses when stimuli were presented with a $\mathrm{NaCl}$ prepulse; open triangles, responses when stimuli were presented with a $\mathrm{HCl}$ prepulse; open squares, responses when stimuli were presented with a quinine prepulse.

Table 2. Effects of taste prepulses on the best stimulus classification of NTS units

\begin{tabular}{llllll}
\hline \multirow{2}{*}{$\begin{array}{l}\text { Best } \\
\text { stimulus }\end{array}$} & $\begin{array}{l}\text { Without } \\
\text { a prepulse }\end{array}$ & \multicolumn{4}{l}{ After a prepulse of: } \\
\cline { 3 - 6 } & $\mathrm{NaCl}$ & $\mathrm{HCl}$ & Quinine & Sucrose \\
\hline $\mathrm{NaCl}$ & $13(27)$ & $22(45)$ & $16(33)$ & $16(33)$ & $19(39)$ \\
$\mathrm{HCl}$ & $17(35)$ & $12(24)$ & $17(35)$ & $15(31)$ & $16(33)$ \\
Quinine & $3(6)$ & $1(2)$ & $2(4)$ & $4(8)$ & $1(2)$ \\
Sucrose & $16(33)$ & $14(29)$ & $14(29)$ & $14(29)$ & $13(27)$ \\
\hline
\end{tabular}

Number of units is indicated with percentage total number of units in parentheses.

(or enhancement), prepulses of different tastants produced different effects. A second possibility might be that present results reflect mixture effects. If this were true, then the response to the prepulse might be expected to overlap the response to the subsequently presented taste stimulus. However, the observation that the water rinse presented in the prepulse-stimulus interval was effective in returning the unit activity to spontaneous rates or below is evidence against the idea that the prepulses had lingering excitatory effects. Moreover, the effects of prepulses were not symmetrical with respect to the order of presentation of taste stimuli. A third possibility is that these effects reflect natural variability in the response magnitude. That is, it can be argued that taste responses in a given unit vary with simple replication, and it is this variability that we are describing. However, results from cells in which tastants were presented more than once showed that this variability was far less than the criterion used to define a significant change in response.

Because the effects of taste prepulses on NTS taste responses are similar to the effects of tetanic electrical stimulation of the CT nerve (Grabauskas and Bradley, 1998; Lemon and Di Lorenzo, 2002), it is possible that the same mechanism may account for both. In both the present study and the study by Lemon and Di Lorenzo (2002), responses to quinine were significantly and selectively attenuated. Because tetanic stimulation bypasses receptor mechanisms, it is unlikely that the effect on quinine responses is of peripheral origin, although it is still possible that $\mathrm{NaCl}$ prepulses may interact with quinine at the periphery. Alternatively, it is possible that the effects of tetanic CT stimulation and of $\mathrm{NaCl}$ prepulses on quinine responses may reflect the interaction of convergent taste nerves onto NTS cells (for a discussion, see Lemon and Di Lorenzo, 2002) because $\mathrm{NaCl}$ is a potent stimulus for the CT (Frank et al., 1983) and quinine is a potent stimulus for the glossopharyngeal nerve (Frank, 1991).

Two results of the present study are consistent with the idea that taste prepulses invoke inhibition. First, attenuation of quinine responses by prepulses of $\mathrm{NaCl}$ and $\mathrm{HCl}$ was no longer present when the prepulse-stimulus interval was lengthened from 1 to $5 \mathrm{sec}$. This agrees with the observation that paired-pulse inhibition in the NTS evoked by CT stimulation could be detected for $<2 \mathrm{sec}$ (Lemon and Di Lorenzo, 2002). Second, the attenuating effects of prepulses were significantly correlated with the magnitude of the responses evoked by both $\mathrm{NaCl}$ and $\mathrm{HCl}$ prepulses. This result is analogous to the observation that higher frequency tetanic CT stimulation produced more profound inhibition in the NTS (Grabauskas and Bradley, 1998).

\section{Effects of taste prepulses on taste coding: a role for dynamic tuning}

The present results are consistent with idea that receptive fields of sensory neurons are dynamic rather than static characteristics of the response properties of a cell. This concept has been illustrated in several sensory systems using paradigms similar to the present one. For example, in the auditory cortex, a brief pure tone burst inhibits, facilitates, or delays the response to another tone depending on the interval between the two stimuli and their respective frequencies (Brosch and Schreiner, 1997). Similarly, in the olfactory system of the moth, a given odor can evoke different responses from the same neurons depending on the temporal pattern of odor presentation (Christensen et al., 1998). These effects are thought to be the result of inhibitory activity. In the gustatory system, the existence of extensive inhibitory interconnections (Davis, 1993; Du and Bradley, 1998; Leonard et al., 1999) suggests that inhibitory interactions may also underlie the dynamic tuning reported here.

The results of the MDS analyses of NTS taste responses show that taste prepulses do not change the interrelationships among across-unit patterns of response for the tastants tested. That is, across-unit patterns produced by sucrose and $\mathrm{NaCl}$ were placed in separate parts of the MDS-defined taste space, whereas acrossunit patterns produced by $\mathrm{HCl}$ and quinine were placed relatively closer together, reflecting their psychophysical similarity (Nowlis et al., 1980; Scott, 1974). When presentation of these stimuli was preceded by a taste prepulse, the basic configuration was unchanged. However, the observation that interstimulus correlations of across-unit patterns were uniformly lower when taste stimuli were preceded by prepulses suggests that, after taste prepulses, there was less overlap of the neural representations of the tastants that were tested.

Although signal units and DTUs may not represent mutually exclusive groups of units, the results of separate MDS analyses of responses from these two groups suggests that units that are relatively unaffected by taste prepulses may serve a different function in the coding process than those units that show significant changes in their responses after taste prepulses. For example, results of an MDS analysis of signal cells alone were not different than that produced by an MDS analysis that included all units. This implies that the responses of units that were unaffected by taste prepulses convey essentially the same information that the system as a whole conveys, i.e., good discrimination among sucrose, $\mathrm{NaCl}$, and $\mathrm{HCl}$-quinine but relatively poor discrimination between $\mathrm{HCl}$ and quinine. In contrast, when DTUs were considered separately, discrimination between $\mathrm{HCl}$ and quinine was much improved.

The division of taste-responsive NTS cells into groups of signal and DTUs (called "noise" cells previously) was originally pro- 

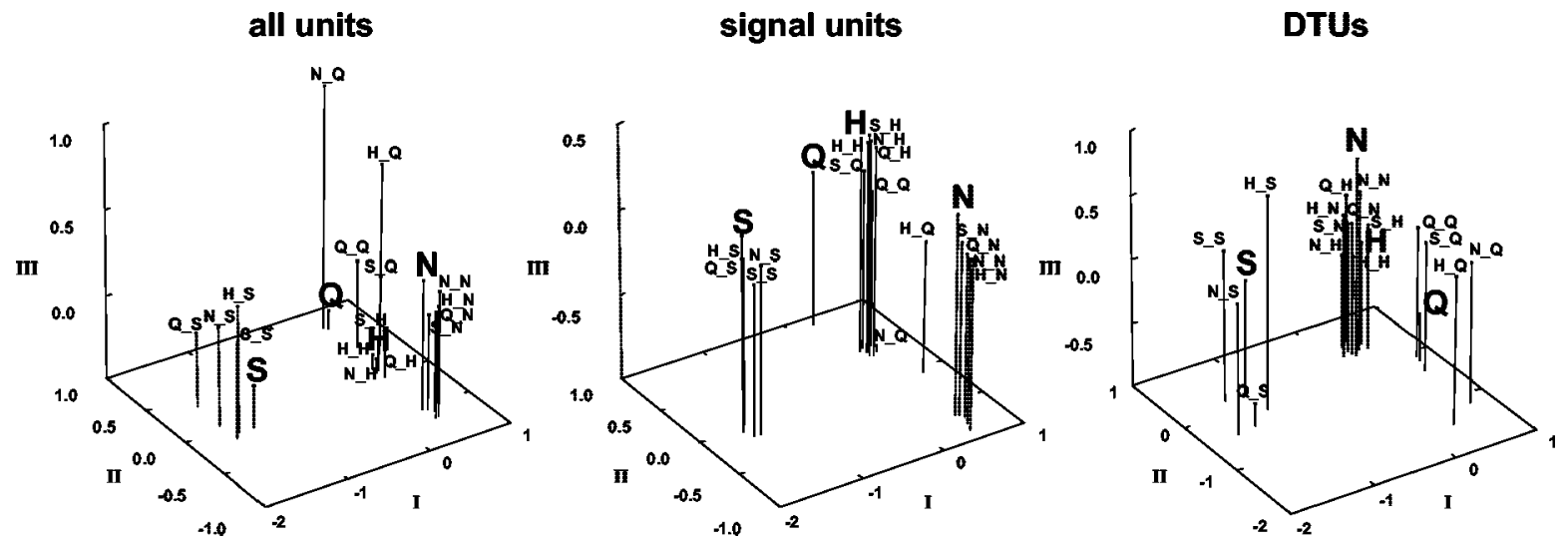

Figure 10. Results of MDS analysis of response profiles to all tastants presented without and after taste prepulses. Left, All units; middle, only signal units; right, only DTUs. Responses to tastants presented without prepulses are indicated by large bold letters. S, Sucrose; $\mathrm{N}, \mathrm{NaCl} ; \mathrm{H}, \mathrm{HCl} ; \mathrm{Q}$, quinine. Responses to tastants preceded by taste prepulses are indicated as follows: first letter indicates $100 \mathrm{msec}$ repulse, underscore indicates $1 \mathrm{sec}$ water rinse, and second letter indicates 3 sec taste stimulus, e.g., N_Q indicates a $100 \mathrm{msec}$ NaCl prepulse, followed by a 1 sec water rinse, followed by a 3 sec quinine presentation.

posed by Di Lorenzo (2000) and was based on preliminary data from the present study. In that paper, a model was described, called dynamic coding theory, that incorporated the effects of prepulses on taste responses reported here. According to this theory, dynamic tuning would be an important feature when complex taste stimuli, i.e., mixtures, are presented to the tongue. Because each taste stimulus within a mixture would be a unique taste condition relative to the other stimuli, present results suggest that the responses encoding that mixture would be dynamically reorganized relative to the responses encoding the components of the mixture presented individually. Units that are unaffected by simultaneously presented tastants, e.g., signal units, would contribute identifying information about a taste stimulus to the across-unit pattern, whereas those units that are affected by recent taste history, e.g., DTUs, would contribute less stimulus-specific information. (Recall that DTUs are generally broadly tuned and therefore by definition convey ambiguous information about taste stimuli.) Theoretically, when mixtures of taste stimuli are presented, the responses of some subset of units would be suppressed (depending on the particular combination of tastants), as they were in the present study after various taste prepulses, but the responses of others would be unaffected. Responses of these unaffected units would become more salient by virtue of an enhanced signal-to-noise ratio. Thus, the interplay of stable (signal) and dynamically tuned (DTUs) taste-responsive cells might form the neural basis for the analytical capabilities of the gustatory system (for a complete discussion of this topic, see Di Lorenzo, 2000).

\section{References}

Brosch M, Schreiner CE (1997) Time course of forward masking tuning curves in cat primary auditory cortex. J Neurophysiol 77:923-943.

Christensen TA, Waldrop BR, Hildebrand JG (1998) Multitasking in the olfactory system: context-dependent responses to odors reveal dual GABA-regulated coding mechanisms in single olfactory projection neurons. J Neurosci 18:5999-6008.

Davis BJ (1993) GABA-like immunoreactivity in the gustatory zone of the nucleus of the solitary tract in the hamster: light and electron microscopic studies. Brain Res Bull 30:69-77.

Di Lorenzo PM (2000) The neural code for taste in the brain stem: response profiles. Physiol Behav 69:87-96.

Di Lorenzo PM, Lemon CH (2000) The neural code for taste in the nucleus of the solitary tract of the rat: effects of adaptation. Brain Res 852:383-397.
Du J, Bradley RM (1998) Effects of GABA on acutely isolated neurons from the gustatory zone of the rat nucleus of the solitary tract. Chem Senses 23:683-688.

Frank ME (1991) Taste-responsive neurons of the glossopharyngeal nerve of the rat. J Neurophysiol 65:1452-1463.

Frank ME, Contreras R, Hettinger T (1983) Nerve fibers sensitive to ionic taste stimuli in chorda tympani of the rat. J Neurophysiol 50:941-960.

Ganchrow JR, Erickson RP (1970) Neural correlates of gustatory intensity and quality. J Neurophysiol 33:768-783.

Giza BK, Scott TR (1991) The effect of amiloride on taste-evoked activity in the nucleus tractus solitarius of the rat. Brain Res 550:247-256.

Grabauskas G, Bradley RM (1996) Synaptic interactions due to convergent input from gustatory afferent fibers in the rostral nucleus of the solitary tract. J Neurophysiol 76:2919-2927.

Grabauskas G, Bradley RM (1998) Tetanic stimulation induces short-term potentiation of inhibitory synaptic activity in the rostral nucleus of the solitary tract. J Neurophysiol 79:595-604.

Hair JF, Anderson RE, Tatham RL, Black WC (1998) Multidimensional scaling. In: Multivariate data analysis, Ed 5, pp 519-574. Upper Saddle River, NJ: Prentice Hall.

Hamilton RB, Norgren R (1984) Central projections of gustatory nerves in the rat. J Comp Neurol 222:560-577.

Lemon CH, Di Lorenzo PM (2002) Effects of electrical stimulation of the chorda tympani nerve on taste responses in the nucleus of the solitary tract. J Neurophysiol 88:2477-2489.

Leonard NL, Renehan WE, Schweitzer L (1999) Structure and function of gustatory neurons in the nucleus of the solitary tract. IV. The morphology and synaptology of GABA-immunoreactive terminals. Neuroscience 92:151-162.

Nowlis GH, Frank ME, Pfaffmann C (1980) Specificity of acquired aversions to taste qualities in hamsters and rats. J Comp Physiol Psychol 94:932-942.

Ogawa H, Yamashita S, Sato M (1974) Variation in gustatory nerve fiber discharge pattern with change in stimulus concentration and quality. J Neurophysiol 37:443-457.

Renehan WE, Jin Z, Zhang X, Schweitzer L (1996) Structure and function of gustatory neurons in the nucleus of the solitary tract. II. Relationships between neuronal morphology and physiology. J Comp Neurol 367:205-221.

Scott TR (1974) Behavioral support for a neural taste theory. Physiol Behav 12:413-417.

Scott TR, Giza B (1990) Coding channels in the rat taste system. Science 249:1585-1587.

Smith DV, Li C-S (1998) Tonic GABAergic inhibition of taste-responsive neurons in the nucleus of the solitary tract. Chem Senses 23:159-169.

Smith DV, Travers JB (1979) A metric for the breadth of tuning of gustatory neurons. Chem Sens Flav 4:215-229. 